\title{
"PARVUS" A MICRO-PARALLEL-SCARA ROBOT FOR DESKTOP ASSEMBLY LINES
}

\author{
Arne Burisch', Jan Wrege ${ }^{1}$, Sven Soetebier', Annika Raatz, Jürgen \\ Hesselbach $^{1}$ and Rolf Slatter ${ }^{2}$ \\ 'Technical University Braunschweig, Institute of Machine Tools and Production Technology \\ (IWF). Langer Kamp 19b, 38100 Braunschweig, Germany; ${ }^{2}$ Micromotion GmbH, Mainz, \\ Germany
}

Abstract: The paper describes the development of a micro-parallel-SCARA robot adapted in size to MEMS products. The degree of miniaturization is optimized concerning a smaller structure but high accuracy in a workspace dimensioned to chip card size. The robot supports the mostly used four degrees of freedom with a base area of less than $150 \times 150 \mathrm{~mm}^{2}$. It is the result of a cooperative project between the Institute of Machine Tools and Production Technology at the Technical University of Braunschweig and Micromotion GmbH. This company is an innovative manufacturer of miniaturized zero-backlash gears and actors, which are used as main drives of the robot.

Key words: desktop factory, micro robot, parallel-SCARA, micro-gears

\section{INTRODUCTION}

Nowadays the trend of miniaturization in product development leads to an increasing gap between the dimensions of the product and the used production systems. Assembly lines for millimeter-sized products often measure some tens of meters. In recent years, the miniaturization of the production systems is discussed in research. Potential for development is seen in economic and technologic benefits of this strategy. On the one hand small dimensions offer the possibility for high modular system designs, improved scalability and flexibility in the manufacturing base of assembly lines. On the other hand small footprints, low power consumption, minor amounts of maintenance and initial costs promise better cost effectiveness. Already in 1990, a research group of the Mechanical Engineering Laboratory 
(MEL) in Japan (Tsukuba) estimated that a $1 / 10$ size-reduction of production machines leads to a decrease of energy consumption about 1/100 compared to a conventional factory ${ }^{1}$.

Nowadays the MEL with its Desktop Machining Factory is deemed to be a pioneer in the field of micro factory ${ }^{1,2}$. Basic ideas and questions related to desktop factories are furthermore discussed by Breguet in his paper "Toward the Personal Factory" ". Deliberating about advantages and disadvantages, he highlights the vision of conventional factories and desktop factories coexisting in future times. The aim should not be the all-purpose desktop factory but a high modular system adapted in size to MEMS as presented in the concepts of Gauge ${ }^{4}$ et al. or Rochdi ${ }^{5}$ et al.. These concepts combine individual assembly modules on a product-neutral platform used for the feeding of parts to individual process stations.

The challenge of the "Parvus Project" was to develop a miniaturized precision industrial robot with the full functional range of bigger models. Independent from its future application area, as a component for a visionary desktop factory or as a miniaturized robot for future assembly lines, some basic requirements had to be determined.

Main questions were the required size of workspace and the striven performance specifications regarding accuracy and velocity. The latter were determined by the presented design studies and the design constraints limited by the available size of system components like servo drives, gearboxes or encoders and switches. An idea of an adequate workspace was given by the size of innovative microproducts by comparing. Product examples, like micro-pumps or labs-on-a-chip as presented by "thinXXS" (see Fig. 1) or the modern RFID transponder led to the size of a chip card.

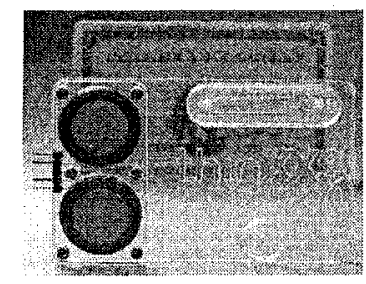

Figure 1. "thinXXS" lab-on-a-chip

\section{STATE OF THE ART FOR PRECISION ROBOTS}

A survey that categorizes precision robots is shown in Fig. 2. The simplest classification is into serial, parallel and hybrid structures, which in turn can be subdivided into further categories. The first category covers 
cartesian robots. These are typically very large in comparison to the components to be handled and are often, as a result, very expensive. However, they do provide repeatability between 1 and $3 \mu \mathrm{m}$, as demonstrated by, for example, the "Sysmelec Autoplace 411". The second category covers SCARA robots, which have a large workspace in relation to their physical size, but only achieve a repeatability of $10 \mu \mathrm{m}$, even in the case of the most accurate designs. In the field of parallel robots, there are few examples in industrial use. The Mitsubishi RP-X is an exception, achieving a repeatability of $5 \mu \mathrm{m}$. Most other developments in this area are limited to university research projects, in particular at the Technical University of Braunschweig in Germany, where extensive experience with parallel structures has been gathered, for example, with the Triglide robot, which has achieved repeatability better than $1 \mu \mathrm{m}^{6,7,8}$.

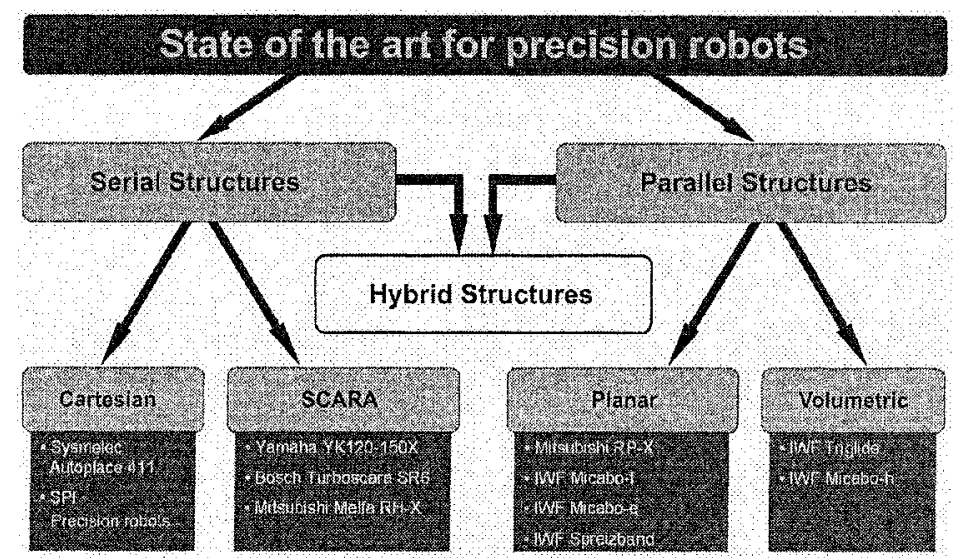

Figure 2. Survey of high precision assembly robots

Nowadays the existing high precision robots are relatively large and expensive. However, a growing market demands for smaller and cheaper robotic devices for precision positioning and assembly is coming up. The minimization of conventional industrial robots is even in progress in commercial products of Yamaha or Mitsubishi. These robots reach a repeatability of $5 \mu \mathrm{m}$.

A further miniaturization of such industrial robots is possible because of new enabling technologies, in particular zero-backlash micro-gears and highly dynamic micro-motors with integrated incremental encoders, which allow proven robot arm structures to be miniaturized. Furthermore they allow the use of proven control technology and avoid the complexity of alternative actuator technologies such as piezo actuators ${ }^{6,8}$. 


\section{INNOVATIVE DRIVE SYSTEMS / COMPONENTS}

In recent years commercially miniaturized DC or EC motors and highresolution encoders came up. In combination with micro-gears, as developed by Micromotion $\mathrm{GmbH}$, these components can serve as adequate drives for micro assembly systems.

The Micro Harmonic Drive ${ }^{\circledR}$ is the only micro-gear currently available that offers the same positioning accuracy as the large-scale Harmonic Drive gears used in industrial robots.

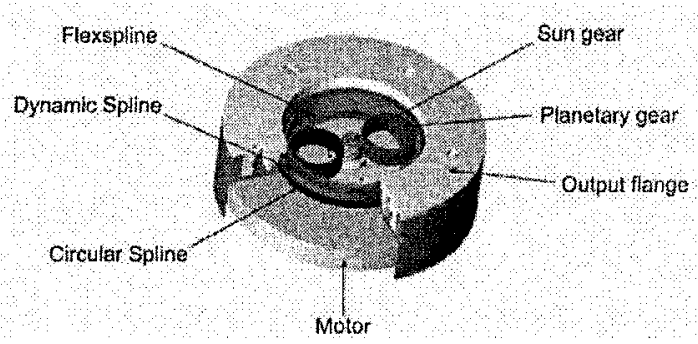

Figure 3. Micro Harmonic Drive ${ }^{\text {(3) }}$ gear components

Fig. 3 shows the basic components of this gear, which uses only six components to achieve reduction ratios between 160:1 and 1000:1. These ratios are necessary to create adequate torques from currently available micro-motors, which are capable of rotational speeds up to $100000 \mathrm{rpm}$, but only offer torques of a few $\mu \mathrm{Nm}$.

Related to the LIGA-technique, the single gear wheels of the Micro Harmonic Drive ${ }^{\circledR}$ are manufactured by electroplating and consist of a nickeliron-alloy. Due to the high yield point of $1500 \mathrm{~N} / \mathrm{mm}^{2}$, the low elastic modulus of $165000 \mathrm{~N} / \mathrm{mm}^{2}$ and its good fatigue endurance, this electroplated alloy possesses the necessary properties for perfect functioning of the flexible gear wheels of this micro gear system.

By providing an angular repeatability of 10 arc seconds, the Micro Harmonic Drive ${ }^{\boxplus}$ gear is the only micro-gear currently available that provides sufficient accuracy for a micro-robot meeting our requirements.

\section{ROBOT DESIGN APPROACHES}

At the beginning of the design phase, some basic specifications were established and quantitative specifications were fixed (see Table 1). The aim was to find a simple modular structure with a small envelope and easy access 
to the working area of the robot. The robot should provide four degrees of freedom (DOF) with three orthogonal translational axes and one additional rotational axis.

Table 1. Requirements

\begin{tabular}{ll}
\hline Criterion & Value \\
\hline Workspace & chipcard-size \\
Footprint (area of robot base) & $<$ DIN-A4 \\
Theoretic resolution & sub- $\mu \mathrm{m}$ \\
Linear speed & $>100 \mathrm{~mm} / \mathrm{s}$ \\
\hline
\end{tabular}

A preselection for a possible kinematic structure of the robot was identified taking a closer look on conventional industrial robots. In this principle design phase, two different plane kinematic structures were compared: the serial "SCARA structure", e.g. used in the Yamaha YK 120, and the "parallel SCARA structure", known from the Mitsubishi RP-1AH .

The decision, whether using the serial or parallel structure, was supported by a detailed positioning sensitivity analysis of both structures. Therefore, the achievable positioning resolution at all points in the chosen workspace of the conceptual designs had to be analyzed. The kinematic transfer functions according the robot drives $q$ and the world coordinates $\rho$ are basically given by the direct kinematic problem (DKP) and the inverse kinematic problem (IKP) of both structures.

$$
\underline{q}=\left(q_{1}, \ldots, q_{F}\right)^{T}, F=D O F \quad \underline{\rho}=\left(X_{T C P}, Y_{T C P}, Z_{T C P}, \Psi_{T C P}\right)^{T}
$$

Depending on geometric parameters, such as number of joints, length of arms and distance between supporting points, the analysis first leads to the workspace of the structure. By calculating from estimated backlash of ball bearings and resolution of the robot drives systems, the matlab-analysis shows the forecasted sensitivity of the structure. Sensitivity $E$ as defined by

$$
E=\frac{\Delta X_{O}}{\Delta X_{1}} \quad \Delta X_{O}=\text { output } ; \Delta X_{1}=\text { input }
$$

is subdivided into sensitivity of the structure $\underline{\underline{J}}$ and sensitivity of dimension tolerance $\underline{\underline{J}}_{M E}$. 


$$
\underline{J}=\frac{\partial \underline{\rho}}{\partial \underline{q}}=\left[\begin{array}{ccc}
\frac{\partial x}{\partial q_{1}} & \cdots & \frac{\partial x}{\partial q_{6}} \\
\vdots & \ddots & \vdots \\
\frac{\partial x}{\partial \varphi} & \cdots & \frac{\partial x}{\partial \varphi}
\end{array}\right] \quad \underline{J}_{M E}=\frac{\partial \underline{\rho}}{\partial \underline{l}}=\left[\begin{array}{ccc}
\frac{\partial x}{\partial l_{1}} & \cdots & \frac{\partial x}{\partial l_{i}} \\
\vdots & \ddots & \vdots \\
\frac{\partial x}{\partial l_{1}} & \cdots & \frac{\partial x}{\partial l_{j}}
\end{array}\right]
$$

Based on the results of sensitivity the theoretical repeatability of the robot's structure is forecasted. The iterative analysis of different geometrical parameters aimed to reach a minimized arm length by keeping a chip-cardsized workspace and high accuracy. The theoretical repeatability, based on accuracy data of drive components, is in some areas better than $1 \mu \mathrm{m}$.

The sensitivity plots of the optimized geometrical structures for serial and parallel kinematics respectively are shown in Fig 4. The serial structure has a theoretical sensitivity map which only achieves high accuracy in very limited areas of the available workspace. The parallel structure, in comparison, achieves high accuracy over almost the complete workspace and also has a symmetrical sensitivity map. Furthermore, the parallel structure should offer a significantly better dynamic performance, because only the gear motor for the fourth (rotational) axis is carried by the moving arm. Additionally the passive joints of the parallel structure are easier to miniaturize than active joints. Because of these reasons, the "parallel SCARA structure" was chosen as the basic structure for further developments. An argument against the parallel structure would be its more complex control due to the closed kinematic structure. Nevertheless, the steady decrease in the cost of computing power means that in this case the mechanical advantages of the parallel structures are more important.

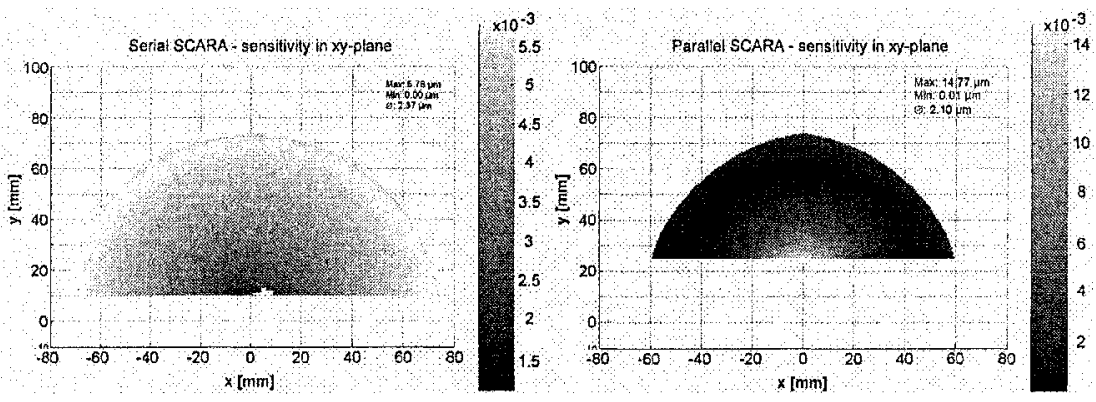

Figure 4. Positioning sensitivity 


\section{DESCRIPTION OF FINAL ROBOT DESIGN}

The results of the design process concerning the basic structure lead to a typical parallel structure shown in Fig. 5. Both active joints $A_{1}$ and $A_{2}$ are equipped with Micro Harmonic Drive ${ }^{(8)}$ gears combined with Maxon DC motors $\left(q_{1}, q_{2}\right)$. They drive the plane structure in $x$-y-direction, whereas joints $B_{1}, B_{2}$ and $C$ are passive in this case.

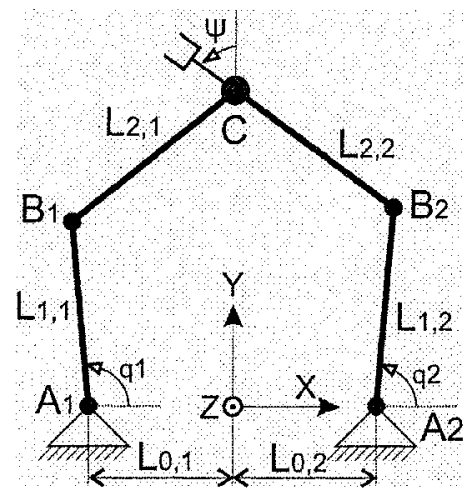

Figure 5. Parallel structure of the robot

Deciding on a plane parallel structure, offering two translational DOF in the $x$-y-plane. The $z$-axis is integrated as a serial axis in the base frame of the robot. The easy handling of the whole plane parallel structure driven in $z$ direction is possible because of its minimized drive components and light aluminum alloy structure. The $z$-axis is driven by a Harmonic Drive servomotor combined with a conventional ballscrew. Additionally the rotational hand axis $\Psi$ was executed as a hollow rotational axis integrated in the passive joint $\mathrm{C}$ as the Tool Center Point (TCP) of the parallel structure. This allows media like e.g. vacuum to be passed along the hand axis. A Micro Harmonic Drive ${ }^{\circledR}$ gear combined with a Maxon EC motor drives the $\Psi$-axis. All joints of the robot are provided with preloaded angular contact ball bearings that are strained by springs. The resulting joints are nearly free of backlash and have low friction.

All servomotors support a high resolution encoder feedback signal. Additionally the Parvus is equipped with magnetoresistive position sensors for initialization of the robot and an emergency stop function.

The control of the Parvus robot was developed on a real-time system from dSPACE Inc. (Germany). The system features a PowerPC750 digital signal processor (DSP) running at $480 \mathrm{MHz}$, a digital $\mathrm{I} / \mathrm{O}$ board, high 
resolution analog $\mathrm{I} / \mathrm{O}$ boards, an encoder board and a serial $\mathrm{I} / \mathrm{O}$ board. The dSPACE system was chosen because of the powerful hardware solution that is available from one supplier and the good operability of the communication software "Control Desk" that was used to create the graphical user interface. For programming the control, dSPACE Inc. gives the possibility to use program codes in "Matlab/ Simulink" and "C".

The first two functional prototypes of Parvus, shown in Fig. 6, are used for further research and presentation at present.

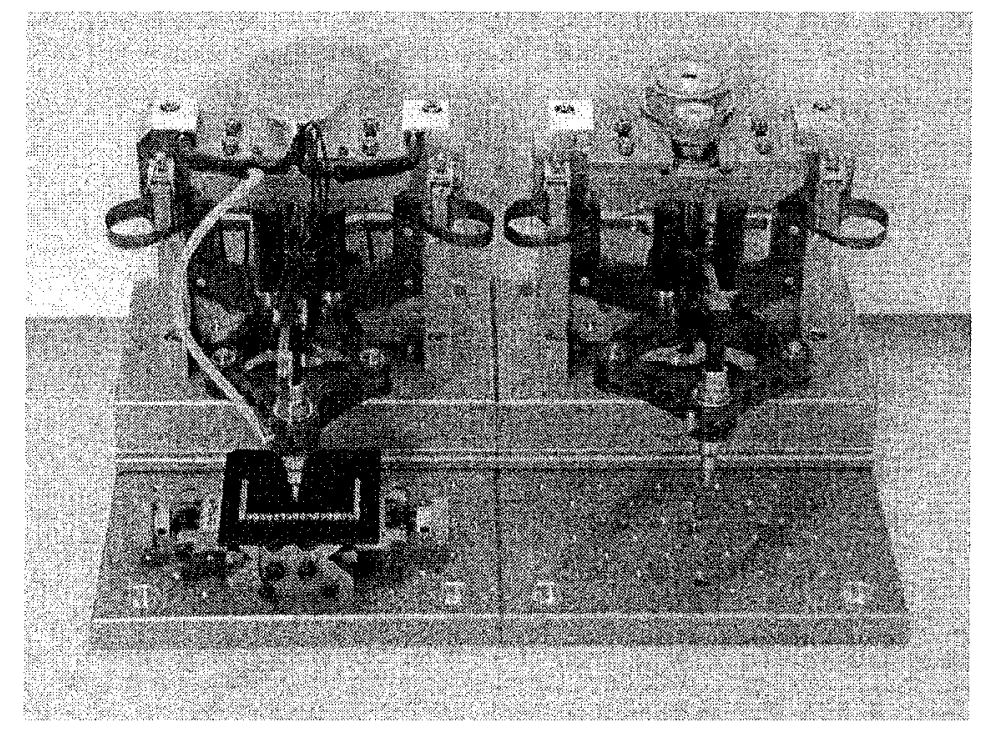

Figure 6. The first two functional models of the Parvus

The first prototype of Parvus fulfills the following specifications shown in Table 2.

Table 2. Technical specifications

\begin{tabular}{lll}
\hline Criterion & Value & Unit \\
\hline Workspace (rectangular) & $60 \times 45 \times 20$ & $\mathrm{~mm}^{3}$ \\
Footprint (area of robot base) & $130 \times 170$ & $\mathrm{~mm}^{2}$ \\
Theoretic resolution & $<3$ & $\mu \mathrm{m}$ \\
Linear speed & $>100$ & $\mathrm{~mm} / \mathrm{s}$ \\
Rotational speed ( $\Psi$ axis) & $187^{*} / 60^{* *}$ & $\mathrm{rmm}$ \\
Angular resolution ( $\Psi$ axis) & $0.022^{*} / 0.007^{* *}$ & $\circ$ \\
Payload & 50 & $\mathrm{~g}$ \\
"ratio $160: 1 /$ / $^{*}$ ratio $500: 1$ & & \\
\hline
\end{tabular}




\section{MEASUREMENTS}

A matlab-analysis based on the kinematic transfer functions mentioned in section 4 led to a linear speed diagram shown in Fig. 7.

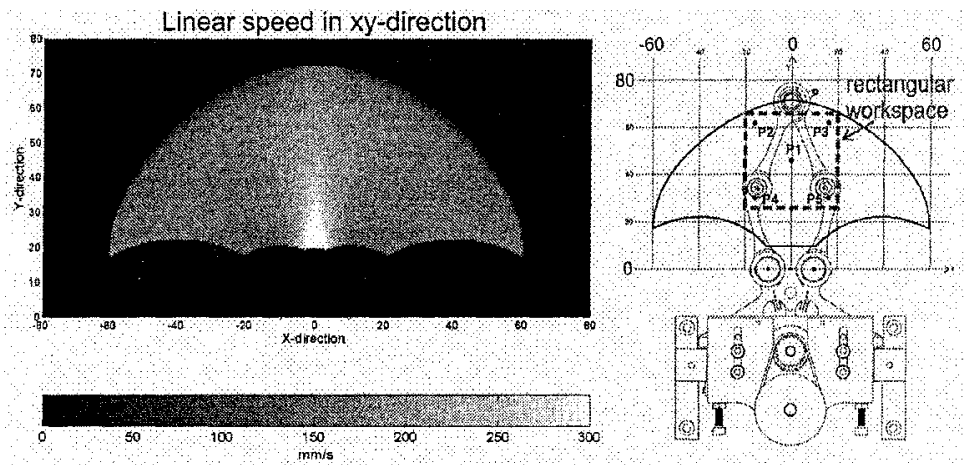

Figure 7. Linear speed diagram and measured workspace of Parvus

Furthermore, performance specifications regarding accuracy were measured at the IWF. The applied test method conforms to the ISO standard EN ISO 9283. The repeatability was measured at five definite points within a rectangular workspace shown in Fig. 7 . Not including point P5, the repeatability of this first prototype was between 5 and $10 \mu \mathrm{m}$. Fig. 8 shows the plots of the best and the worst result. As expected, the practically measured repeatability is lower than the forecasted high theoretical accuracy. Experiments demonstrate that influences of elasticity in the drive components may be responsible for this effect.
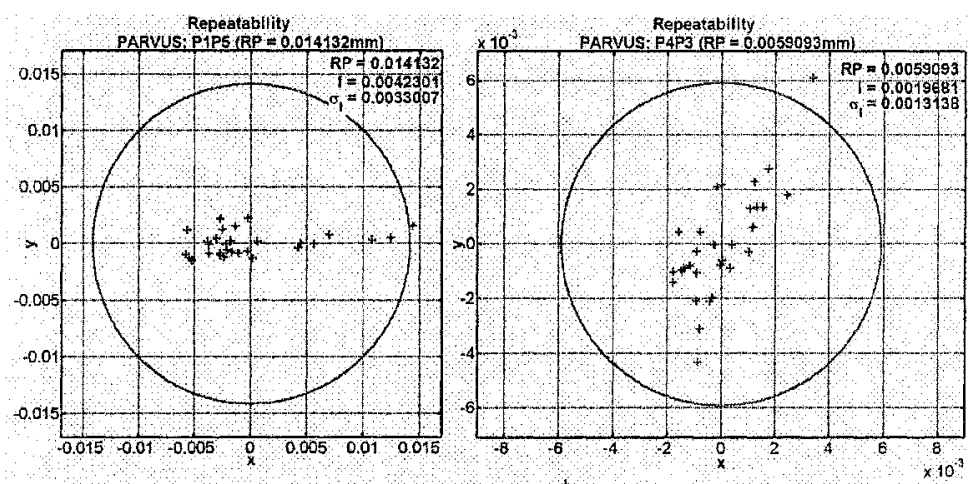

Figure 8. Results of repeatability 


\section{CONCLUSION AND OUTLOOK}

The prototype of the robot (Fig. 6) was demonstrated to the public at the Hanover Fair in April 2005 for the first time. The feedback of industrial partners gives good perspectives using the Parvus in a visionary desktopfactory. Concerning the accuracy parameters of the robot, there will be further efforts to optimize the robot's structure and drive mechanism. Meanwhile the micro-gears are available with an optimized tooth profile, better accuracy and stiffness. Hence, the improved Parvus will guarantee a much better repeatability than $10 \mu \mathrm{m}$.

\section{REFERENCES}

1. Y. Okazaki, N. Mishima, K. Ashida, Microfactory and Micro Machine Tools, Proc. of Korean-Japan Conference on Positioning Technology, Daejeon, Korea, 2002

2. M. Tanaka: Development of Desktop Machining Microfactory, RIKEN Review No. 34 , (April, 2001).

3. J.-M. Breguet, A. Bergander, Toward the Personal Factory?, Proc. of SPIE, Microrobotics and Microassembly III, Vol. 4568, pp. 293-303, (2001).

4. T. Gaugel, M. Bengel, D. Malthan, Building a Mini-Assembly System from a Technology Construction Kit, Proc. of International Precision Assembly Seminar IPAS'2003, (17-19 March, Bad Hofgastein, Austria, 2003).

5. K. Rochdi, Y. Haddab, S. Dembélé, N. Chaillet, A Microassembly Workcell, Proc. of International Precision Assembly Seminar IPAS 2003, (17-19 March, Bad Hofgastein, Austria, 2003).

6. J. Hesselbach, A. Raatz, J. Wrege, S. Soetebier, Design and Analysis of a Macro Parallel Robot with Flexure Hinges for Micro Assembly Tasks, Proc. of 35th International Symposium on Robotics (ISR), No. TU14-041 fp, (23-26 March, Paris, France, 2004).

7. J. Hesselbach, G. Pokar, J. Wrege, K. Heuer, Some Aspects on the Assembly of Active Micro Systems, Production Engineering Vol. XI/1, pp. 159-164, (2004).

8. J. Hesselbach, J. Wrege, A. Raatz, O. Becker, Aspects on Design of High Precision Parallel Robots, Journal of Assembly Automation Vol. 24 No. 1, Emerald, pp. 49-57, (2004). 